\title{
LEADING VIRTURAL TEAMS DURING COVID-19
}

\author{
Nicoleta Dorina RACOLȚA-PAINA ${ }^{a^{*}}$, Alexandra LUNCAȘU ${ }^{b}$, Maria METZ $^{c}$, \\ Sergiu Eugen Z $\breve{A G A N^{d}}$
}

${ }^{a, b, c, d}$ Babeş-Bolyai University Cluj-Napoca, Romania

\begin{abstract}
The context given by the COVID-19 pandemic has led to the implementation of the mandatory work from home (MWFH), a concept well known nowadays. The teams had to adapt and to become 100\% virtual in a really short period of time in order to ensure the continuity of the activities for the businesses. Team leaders suddenly became team leaders of virtual teams; thus, this had implied the shift from team leadership to virtual team leadership. The effectiveness of virtual team leaders remains a desideratum for companies, taking into account that now team leaders work in a unique context given by the COVID-19 pandemic situation.

The purpose of this research is to analyse the way of working of a $100 \%$ virtual team, from a Shared Service Centre located in Cluj-Napoca, Romania, for the time frame March 2020 - March 2021. The case study was performed based on quantitative and qualitative empirical research; the primary data being collected from the targeted virtual team. Firstly, the focus is on presenting the organizational context based on the influence of the COVID-19 pandemic and secondly, the decisions taken by the management during this period in order to maintain the $100 \%$ virtual team performance are analysed. Several aspects at the analysed team level are identified, based on the perception of its team members, such as the level of connection, the sense of belonging to the team, engagement, cohesion, team coordination level, individual productivity in the MWFH environment and last, but not least, the team productivity level in the pandemic period versus the period before the COVID-19 pandemic. The main conclusions of this case study are reflecting that the level of individual productivity and also the level of the team productivity have remained at a constant level, which is indicating that the effectiveness of team leadership has been maintained at a high level. However, some of the analysed aspects such as, level of connection, team cohesion and the sense of belonging to the team, were negatively influenced by the virtual way of working despite the management decisions taken in order to support the virtual team environment.
\end{abstract}

KEYWORDS: virtual teams, leadership, COVID-19, case study, Romania.

\section{INTRODUCTION}

As The current context given by the COVID-19 pandemic has a major impact on the business environment, starting with March 2020 when the companies had to adapt urgently to the unexpected and unprecedented situation. Therefore, at global level, the work from home policy was implemented at a very large extent, rapidly and totally unplanned (PwC, 2020, p. 2). Based on a study issued by the Eurofound (2020, p. 5), "over a third (37\%) of those currently working in the EU began to telework as a result of the pandemic". Considering the aspects mentioned, the virtual teams had become the new way of organization for the business environment, and this in just a period of few weeks (CIPD, 2020, p. 2), most of the employees started to work from home (WFH).

\footnotetext{
*Corresponding author. E-mail address: nicoleta.paina@ubbcluj.ro
} 
Therefore, the COVID-19 pandemic context had transformed the WFH from a benefit given to the employees into the only option available to continue working by keeping the risk of exposure to the virus to a minimum level (Bonacini et al, 2021). Thus, there is so-called mandatory work from home (MWFH) (Kniffin et al, 2021, p. 65), characterised by some distinguished elements, such as "forced, unprepared, and brutally imposed" (Dolce et al, 2020, p. 2).

Currently (April 2021), after more than a year after the outbreak of the pandemic caused by coronavirus, the employees from several companies are still working from home, being part of a virtual team, without having the possibility to interact face-to-face with their colleagues. An area where this situation predominates is the one of the so-called service centres (Shared Services Centres SSCs). Usually, these centres are serving a global group, the services being provided with the support of information and communication technology (ICT), regardless of the specific domain: financial-accounting services, human resources, logistics, procurement, etc. Bearing in mind all the above mentioned, it is important to highlight our focus on analysing the effectiveness of the team leaders of the $100 \%$ virtual teams, their actions, respectively the perception of the team members about the several aspects that are describing the work during the COVID-19 pandemic. The proposed case study is performed at the level of a virtual team from a department (referred from now on Team A, respectively, Department A for confidentiality reasons) part of the procurement function from a multinational company, leader in the transportation industry due to its innovative transport solutions and high attention to environmental protection. The department A is based in the Shared Service from Cluj-Napoca, Romania and is providing services in the human resources area, financial services and procurement. This decision came somewhat naturally, given that the Romanian business services market is a growing one, being dominated by BPOs (Business Process Outsourcing), SSCs (Shared Service Centres), R\&Ds and ITOs, which are supporting different areas (IT, banking, telecommunications, automotive, FMCG, etc.), most of them exporting those services $(E Y, 2019)$. According to the mentioned source, the companies which are in the services business are based mostly in Bucharest and in Cluj-Napoca, but there are some tendencies to expand also in other Romanian cities, such as Timișoara, Iași and Braşov. Related to the management team of Team A (virtual team, starting with March 2020) it is important to mention that it is formed from 3 members who are leaders of the 36 team members, all with university degrees. We have chosen this team because the team members profile is matching the profile identified by Eurofound for the persons working from home, more precisely, "disproportionately urban-based, white-collar, well-educated, service sector employees" (Eurofound, 2020, p. 3). Secondly, all the team members are meeting the criteria related to the mandatory remote workers as a result of the decision taken due to the COVID-19 pandemic context. Moreover, we have decided to consider this team for the case study of this research because of the complexity of the tasks of the leaders of this team, as one of their main roles is to provide "some stability in very unstable times" (CIPD, 2020, p. 2).

The case study done in Team A is built on a series of primary and secondary data. The primary research conducted was both qualitative (through the direct observation of one of the authors of this research who is a member of Team A) and quantitative. The survey-based research was conducted among the 36 team members from Team A (management team was excluded), in April 2021.

The contribution of this paper for the specialized literature. related to the topic of leading virtual teams during the COVID-19 pandemic, has a practical character based on the case study proposed. In short, our main interest for this study is the way of working of the $100 \%$ virtual teams, the work of their team members in the MWFH environment, the emphasis being on team leaders. Moreover, the analysed team is presented by giving details about the complex organizational context triggered by the COVID-19 pandemic, and the decisions and actions of the team leaders in order to achieve the performance goals in the new normal context. 


\section{LITERATURE REVIEW}

The COVID-19 pandemic has led, most probably, to the highest level of presence of virtual teams in the organizational environment (CIPD, 2020). The response of the specialists in this area, had popped up immediately, noticing that the teams adapted quickly to the new way of working, more specifically, "100\% remote" (PwC, 2020). As a result, a unique situation can be noticed related to the virtual teams, during the COVID-19 pandemic, because the new way of working for all team members is " $100 \%$ remote" and MWFH respectively. This total virtuality of the teams is representing a great challenge for proper way of working (CIPD, 2020) and the team leaders are playing an important role in this. Kniffin et al (2021) highlighted the forced dimension of workfrom-home (WFH) during COVID pandemic time and hence the MWFH concept. Andrei (2021) also referred to mandatory WFH experienced by employees in the knowledge-intensive business services (KIBSs) due to COVID-19 pandemic.

Similar with the traditional teams, the team leaders of the virtual team are targeting the team performance increase and the team success (Anoye \& Kouamé, 2018). Jibai and Abdallah (2019, p. 968) have recently highlighted "the existence of an extremely generous space of maneuver, regarding the methods, techniques and tools used to increase the performance of the team". Moreover, the leaders have to prove that they have a series of cognitive, social and behavioural capabilities, no matter the leadership style used, either a transactional or a transformational one (Mukherjee et al, 2012) (see Table 1).

Table 1. Leadership capabilities required for effective management of virtual teams

\begin{tabular}{|c|c|c|}
\hline \multicolumn{3}{|c|}{ Transactional leadership } \\
\hline Cognitive capabilities & Social capabilities & Behavioural capabilities \\
\hline $\begin{array}{l}\text { - used in order to define standards and } \\
\text { objectives; } \\
\text { - start from a previously used logic; } \\
\text { - bear in mind the incremental change, } \\
\text { effectiveness and continuity; } \\
\text { - contribute to creating the conditions } \\
\text { needed to focus on purpose; } \\
\text { - contribute to the monitoring of } \\
\text { deviations. }\end{array}$ & $\begin{array}{l}\text { - focus on strengthening } \\
\text { strategy and culture; } \\
\text { - contribute to providing } \\
\text { support and resources for } \\
\text { employees; } \\
\text { - ensure the process of the } \\
\text { "exchange" of rewards for } \\
\text { performance. }\end{array}$ & $\begin{array}{l}\text { - contribute to the construction of } \\
\text { clear arguments; } \\
\text { - with role in providing constructive } \\
\text { feedback; } \\
\text { - help strengthen the importance of } \\
\text { learning; } \\
\text { - contribute to the internal processes; } \\
\text { - ensure the introduction of corrective } \\
\text { actions when deviations from the } \\
\text { established standards occur. }\end{array}$ \\
\hline \multicolumn{3}{|c|}{ Transformational leadership } \\
\hline Cognitive capabilities & bilition & Behavioural capabilities \\
\hline $\begin{array}{l}\text { - contribute to the recognition of growth } \\
\text { and development needs at the } \\
\text { followers' level; } \\
\text { - important in identifying the way to } \\
\text { inspire, stimulate, increase loyalty } \\
\text { and trust; } \\
\text { - support a divergent way of thinking in } \\
\text { order to build innovative strategies. }\end{array}$ & $\begin{array}{l}\text { - help to relate to individual/ } \\
\text { group needs; } \\
\text { - lead to the involvement of } \\
\text { individuals / groups; } \\
\text { - ensure the importance of } \\
\text { the human relation roles; } \\
\text { - useful in consulting with } \\
\text { individuals or groups. }\end{array}$ & $\begin{array}{l}\text { - lead to the inspiration of those } \\
\text { around them, intellectual } \\
\text { stimulation; } \\
\text { - focus on continuous learning and } \\
\text { innovation; } \\
\text { - give priority to expression, risk- } \\
\text { taking and provocative rules; } \\
\text { - important role in the coaching of the } \\
\text { followers and in giving feedback. }\end{array}$ \\
\hline
\end{tabular}

Source: adapted from Mukherjee et al (2012, p. 278) 
It is important to mention that both leadership styles (transactional and transformational) connect in certain areas, being more complementary rather than opposite styles (Hamilton, 2009). This aspect is essential to be mentioned in order to better understand why the team leader of the virtual teams holds and uses capabilities that fit into both leadership styles.

Focusing on the specific aspects of remote work, a study published by Deloitte (2020, p.1) highlights that the managers of virtual teams have an essential role in the definition of the expectations related to the work output and workload, the other aspects being decided at the company level (such as access to technology) or influenced by the situation of each employee (such as a dedicated space for work in their home) (see Table 2).

Table 2. Work of virtual team leaders

\begin{tabular}{|c|c|}
\hline $\begin{array}{l}\text { Aspects defined by the remote work } \\
\text { (WFH) }\end{array}$ & Actions of the virtual team leaders \\
\hline $\begin{array}{l}\text { - those related to access to technology, } \\
\text { more specifically a computer with } \\
\text { video chat capability, good internet } \\
\text { connection, chat apps, collaboration } \\
\text { apps; } \\
\text { - those related to physical space, a } \\
\text { dedicated workspace; } \\
\text { - those related to employee behaviour, } \\
\text { such as clear expectations on work } \\
\text { output and workload, self-motivation } \\
\text { and discipline, routine. }\end{array}$ & $\begin{array}{l}\text { - review and update the responsibilities of each team member to } \\
\text { ensure clarification of roles and objectives; } \\
\text { - implement a team-level communication that is open and } \\
\text { consistent; } \\
\text { - establish together with the team members the essential aspects, } \\
\text { such as, defining what is "reachable, responsive and } \\
\text { dependable". } \\
\text { This implies, also, the clear definition of what "urgent" means } \\
\text { and what is the best way to contact a team member in these } \\
\text { cases. } \\
\text { - other aspects, for example: } \\
\checkmark \text { Dedicate a special slot in the daily team meetings to discuss } \\
\text { about what's going well; } \\
\checkmark \text { Encouragement of the team members to use all the resources } \\
\text { they have in terms of technology in order to increase the } \\
\text { virtual collaboration. }\end{array}$ \\
\hline
\end{tabular}

Source: adapted from Deloitte (2020, p. 1)

Bearing in mind all the above mentioned, it is important to say that the management of the virtual teams is taking place in an organizational context, in which the team leaders have to adapt and to identify the right actions in order to create a favorable framework and to increase the performance of employees.

\section{CASE STUDY}

\subsection{Research methodology}

The proposed case study, realized in Team A from the multinational company in Cluj-Napoca, Romania, aims to identify the actions that can be taken by the management of the team, keeping in mind that this team had become a virtual one in a short period of time (end of March 2020). Most of the Team A members had limited experience or no experience in working from home until that moment. Additionally, the global uncertain situation had influenced the decisions taken in the shared service out of which Team A is located, the organizational context being a complex one.

This research is based on primary and secondary data, the time frame considered being March 2020 - March 2021. The secondary data used for the case study are represented by several internal documents from Department A, one of the authors being an employee in this department. Next, the primary data used for this case study have been collected using both qualitative and quantitative methods, including observation and survey-based research. Thereby, some of the primary data used 
for the case study were collected through personal observation of one of the authors of the research. These data are represented by the management decisions which defined the organizational context for the virtual team for the Shared service where Team A and its management are located. The survey-based research was addressed to the team members of Team A, the management team, formed from 2 senior team leaders and one manager, being excluded.

The survey, which included a number of 11 questions, was distributed online via Microsoft Forms in April 2021. The response rate to the survey was 83\% (30 out of the total of 36 team members of

Team A completed the survey). We believe that it is a very good response rate that ensures that the data collected are relevant to Team A.

The data collected were aimed to capture the perception of the respondents about:

- connecting team members to each other, their sense of belonging and commitment, team cohesion and level of coordination;

- the individual productivity in the telework regime, respectively the productivity of the virtual team compared to the period before the COVID-19 pandemic.

We took the decision to identify the perception of the virtual team members from the analysed team because we consider these elements essential for the decision-making process in the future of the management of the team or even the management of the Shared Service analysed.

Through the analysis and interpretation of the primary data collected, this case study contains a series of suggestions in terms of managerial approaches to counteract the identified negative aspects and to strengthen the positive aspects identified at the level of the analysed team.

\subsection{The analysis}

As mentioned before, Team A had become a virtual team at the end of March 2020, based on the decision taken by the management team of the SSC, of which Department A is part of. In fact, the employees had started to work in the MWFH regime, in Romania being instituted a state of emergency. Keeping in mind that Team A has 39 team members, three out of them being part of the management team ( 2 senior team leaders and one manager), the team members are clustered in three sub-teams with approximately 12 members each.

Department $\mathrm{A}$ is reporting directly to the Central function of the multinational company, providing procurement and supply chain services support. The main scope of this department is achieving excellence related to the processes and procurement tools and also to support the implementation of the digitalization strategy and governance at a global level. The main activities of Department A are focused on providing analyses and reports in order to support the strategic initiatives and implementation of the projects; creation and development of KPIs, Dashboards, tools development and maintenance and governance at global level in order to achieve the desired results. The roles from this team are designed for each team member to become the expert in that area and important to mention is that usually other 2 colleagues are familiar with that process from back-up and business continuity plan. Even before March 2020, for the members of Team A there was the possibility to choose to work from home a maximum of 4 days each month, but all the time it was a hybrid way of working as part of the team was at the office, and the other part working remotely. Starting from January 2021, the management gave the possibility to the team members of virtual Team A to choose to work from the office, but by respecting a maximum $20 \%$ occupation of the office floor. Even with this option available, few members are choosing to go to the office and in the most cases when this option is used is because they have some Internet connection or electricity problem when working from home. Thus, this is in accordance with many employers' expectations that "their employees will work from home after the crisis end" (Iorganda (Voda) \& Roman, 2020, p. 819).

Some characteristics of the team members (Team A) are:

- $50 \%$ of Team A members are between the ages 31 and $40,46 \%$ are under 31 years old, the rest being over 41 years old. The average age at team level is 31 years. 
- There is a gender balance in Team A, with only a slightly higher number of male employees $52 \%$ (management team included).

- All the team members finished university studies, about a third had graduated economic studies, followed by the ones that studied social-human science, respectively engineering studies. In the team there are also graduates from administrative studies, social science, communication and dentistry.

- In terms of working experience, the majority is represented by employees with an experience between 4 and 10 years, followed by the employees with an experience higher than 10 years. But there is one team member with experience under 3 years.

Immediately, after the members of Team A had started to work in the MWFH system, the top management of the company implemented a series of actions with the purpose to ensure the continuation of the operations in the "new normal" (see Table 3 ).

Table 3. Decisions made by top management (March 2020 - October 2021)

\begin{tabular}{|l|l|}
\hline \multicolumn{1}{|c|}{$\begin{array}{c}\text { The content of decision-making } \\
\text { (time of decision-making / time of } \\
\text { revised decision-making) }\end{array}$} & \multicolumn{1}{c|}{ Ways of implementing decisions } \\
\hline $\begin{array}{l}\text { Ensuring the work condition needed for } \\
\text { the remote work (April 2020) }\end{array}$ & $\begin{array}{l}\bullet \text { Give the possibility to the employees to use the company equipment } \\
\text { (such as ergonomic chair, monitor, keyboard) from home. }\end{array}$ \\
\hline $\begin{array}{l}\text { Electronic communication infrastructure } \\
\text { (June 2020) }\end{array}$ & $\begin{array}{l}\text { - The migration to Microsoft Teams from Skype for Business provided to } \\
\text { the employees the possibility to have video meetings and a lot of other } \\
\text { benefits for communication compared with the previous solution. }\end{array}$ \\
\hline $\begin{array}{l}\text { Internal reorganization with direct impact } \\
\text { on Team A } \\
\text { (October 2020) }\end{array}$ & $\begin{array}{l}\bullet \text { New team members in the Team A; } \\
\text { - New manager for the Team A; } \\
\text { - A new senior team leader for one of the teams from the Department A. }\end{array}$ \\
\hline
\end{tabular}

Source: the authors

At their turn, the management team of Team A had taken and implemented a series of decisions with the aim to support the team members in achieving the objectives (see Table 4).

These factors are:

- the transformation of the team into a full virtual team in this really short period of time, at the end of March 2020, following the management decision to introduce MWFH for all the employees due to the COVID-19 pandemic context.

- the increase of the workload for Team A, in terms of reports and analysis provided to the central team (represented by development of new KPIs and analyzing the performance of certain suppliers or the PSC (Procurement and Supply Chain) performance of the production sites, data quality improvements, suppliers CSR screenings, etc.). The activities covered by Team A are represented by a very wide range of reports and analyses in order to support the global activities of the multinational company.

- a new organizational situation in 2021 (compared with previous years), given by the lack of the financial incentives as the salary review process didn't take place.

Table 4. Decisions made by team leaders of analyzed virtual team (March 2020 - January 2021)

\begin{tabular}{|l|l|l|}
\hline $\begin{array}{c}\text { The content of decision-making } \\
\text { (time of decision-making / time of } \\
\text { revised decision-making) }\end{array}$ & Ways of implementing decisions & Ways of implementing revised decisions \\
\hline $\begin{array}{l}\text { Formal communication } \\
\text { (end of March 2020/ January 2021 } \\
\text { - revised decision) }\end{array}$ & $\begin{array}{l}\text { - short morning meetings with } \\
\text { the teams daily; } \\
\text { weekly one-hour team meetings } \\
\text { with focus on: }\end{array}$ & $\begin{array}{l}\text { the short daily meetings were reduced to a } \\
\text { number of 3 sessions per week, based on } \\
\text { the feedback received from the teams. } \\
\text { the weekly team meeting was kept in the } \\
\text { same structure and recurrence. }\end{array}$ \\
\hline
\end{tabular}




\begin{tabular}{|c|c|c|}
\hline $\begin{array}{l}\text { The content of decision-making } \\
\text { (time of decision-making / time of } \\
\text { revised decision-making) }\end{array}$ & Ways of implementing decisions & Ways of implementing revised decisions \\
\hline & $\begin{array}{l}\text { leam updates; } \\
\text { communication at team level; } \\
\text { activities in order to increase the } \\
\text { level of communication (new } \\
\text { processes presentation); } \\
\text { people (team games with the } \\
\text { role to get to know each other). }\end{array}$ & \\
\hline $\begin{array}{l}\text { Development of the team members } \\
\text { (March } 2020 \text { / October 2020) }\end{array}$ & $\begin{array}{l}\text { - monthly 1-2-1 video meeting } \\
\text { with each team member and the } \\
\text { team leader, the focus being } \\
\text { mainly on the development } \\
\text { opportunities of the team } \\
\text { member. }\end{array}$ & $\begin{array}{l}\text { - bi-weekly } 1-2-1 \text { video meeting with each } \\
\text { team member and the team leader, the } \\
\text { focus being mainly on the development } \\
\text { opportunities of the team member. }\end{array}$ \\
\hline $\begin{array}{l}\text { Informal communication } \\
\text { (December 2020) }\end{array}$ & $\begin{array}{l}\text { - team meetings to discuss } \\
\text { different topics such as coffee } \\
\text { versus tea, Holiday customs } \\
\text { sharing etc. }\end{array}$ & $\begin{array}{l}\text { - organization of live meetings with the } \\
\text { team in order to play board games ( } 2 \mathrm{~h} \\
\text { per month), going out in the park. All } \\
\text { these activities by respecting the social } \\
\text { distance and sanitary rules. }\end{array}$ \\
\hline
\end{tabular}

\section{Source: the authors}

All the above mentioned are defining the context in which Team, $100 \%$ virtual, had fulfilled all the tasks and deliverables in the period March 2020 - March 2021.

Based on the survey distributed to the team members of Team A (30 out of the total of 36 members targeted), the perception of the respondents related to the work in a fully virtual team is detailed in the next section.

Regarding the connection of the team members, $16(53 \%)$ of the respondents disagree with the statement "I feel highly connected to my team as we work remotely", 8 (27\%) of the respondents agree with the statement, and 4 respondents chose the neutral answer (neither agreement, nor disagreement with the statement). (see Figure 1).

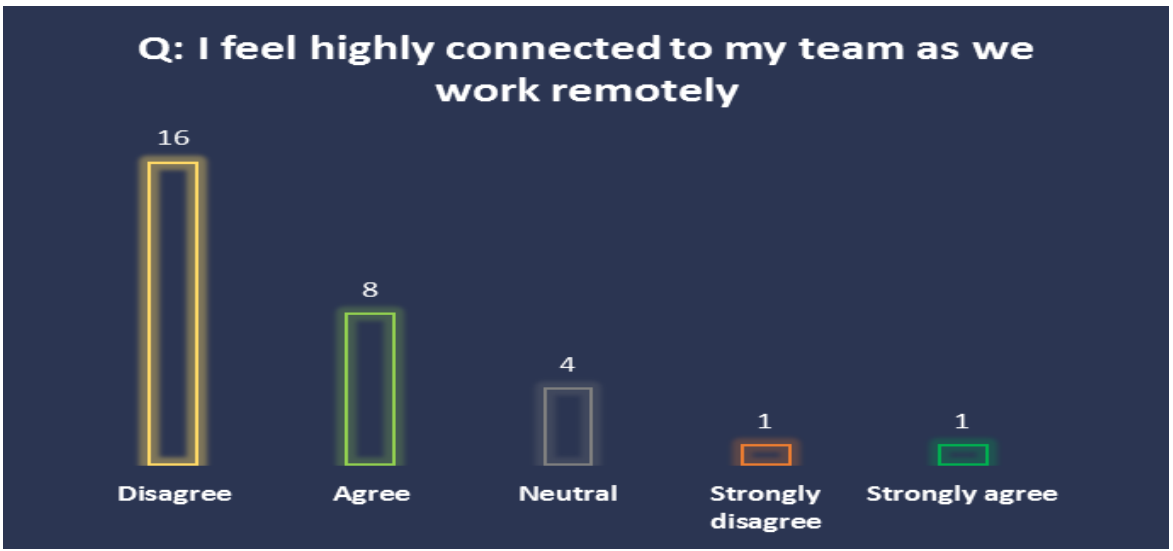

Figure 1. Distribution of respondents (number) according to the answer given to Question 1 (Survey)

Source: the authors

According to the data collected (see Figure 1), the degree of connection at the level of Team A is one of the aspects that were negatively influenced by the transition to the MWFH, but is not a fact perceived unanimously by the 30 respondents to this survey-based research. Therefore, for 9 (30\%) of the members the individual connection level has increased with the rest of the team even if the team is $100 \%$ virtual. 
Regarding to the sense of belonging to the team, $20(67 \%)$ of the respondents agree with the statement "I feel that the sense of belonging to the team has decreased comparatively before working remotely", followed by a number of $4(13 \%)$ respondents who strongly agree with the statement, whereas another 4 respondents have a neutral opinion.

About the engagement of the members from Team A, 11 (37\%) of the respondents agree with the statement "I think that the level of engagement of the team members has reduced compared with the pre-pandemic period", the same number of 11 respondents are in disagreement with the mentioned statement. A number of 5 respondents have a neutral opinion, 2 are strongly agreeing with the statement and only 1 respondent totally disagrees. As a result, according to the 30 respondents to the survey there is no clear trend (decrease or increase) of the engagement level. The perception on this topic was practically divided on this issue.

If we are taking a deeper look to the cohesion level of the team, $19(63 \%)$ of the respondents agree with the statement "I feel that the level of cohesion of the team has decreased since working remotely.", an equal number of 4 respondents disagree, respectively are neutral about this statement, and lastly a number of $3(10 \%)$ respondents strongly agree with this statement. Thus, the identified situation from Team $\mathrm{A}$ is represented by a decreasing trend related to the level of cohesion since the transition to $\mathrm{MWFH}$, this fact is also strengthened by the results related to the sense of belonging (detailed above).

The next topic that we would like to refer to is related to the Team A's perception related to the coordination level compared with the period before the transition to the MWFH regime. According to the data collected (see Figure 2), $11(36 \%)$ of respondents have a neutral opinion related to the statement "I consider that the level of coordination at the team level has increased compared to the pre-pandemic period.", 9 (30\%) of the respondents agree with this statement, and an equal number of respondents are in disagreement.

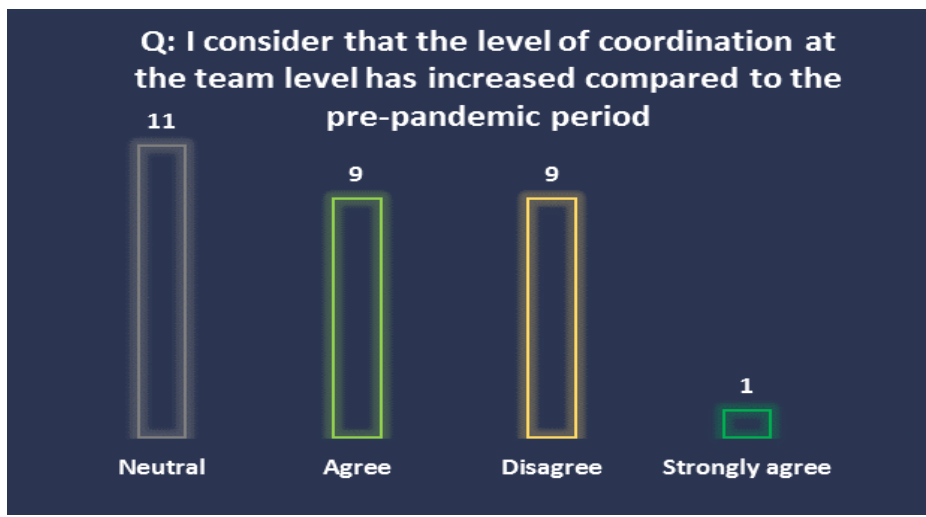

Figure 2. Distribution of respondents (number) based on their feedback related to the team coordination level

Source: the authors

These results show that, according to the perception of the respondents to this survey-based research, there is a variety of views related to the transition to the MWFH regime when it comes to the level of coordination. Thus, although the respondents consider that the level of connection, belonging and cohesion had decreased in the period March 2020 - December 2020, related to the engagement and coordination levels, the opinions of the respondents are divided with almost equal balance between the number of those who chose opposite answers. It is important to remark that over a third of the total number of respondents to the survey (more precisely $36.66 \%$ ) had selected a neutral answer to the statement "I consider that the level of coordination at the team level has increased compared to the pre-pandemic period." 
In order to identify the way in which the MWFH regime influenced the productivity of the team members from Team A, the survey included the dichotomous question "Has working from home affected your productivity?" and the respondents had to choose between yes or no in order to answer. As a result, $25(83 \%)$ of the respondents selected the answer no. The explanations from the 5 respondents who had chosen the answer yes to this question are:

- The fact that they don't spend time getting to work and can allocate more time to professional activities has led to an increase in the productivity level in the regime of working from home for 2 respondents.

- It is more difficult to concentrate and to maintain their focus while working from home; as a result the productivity level of 2 respondents has decreased.

- One respondent chose not to provide details.

The above result is reinforced by the degree of agreement of the respondents to the statement „I feel that I am as productive working from home as I am in my normal working environment". Therefore, $83 \%$ of the respondents (15 respondents agree with the statement and 10 totally agree) consider that they are just as productive in the MWFH regime as they are when working from the office. (see Figure 3).

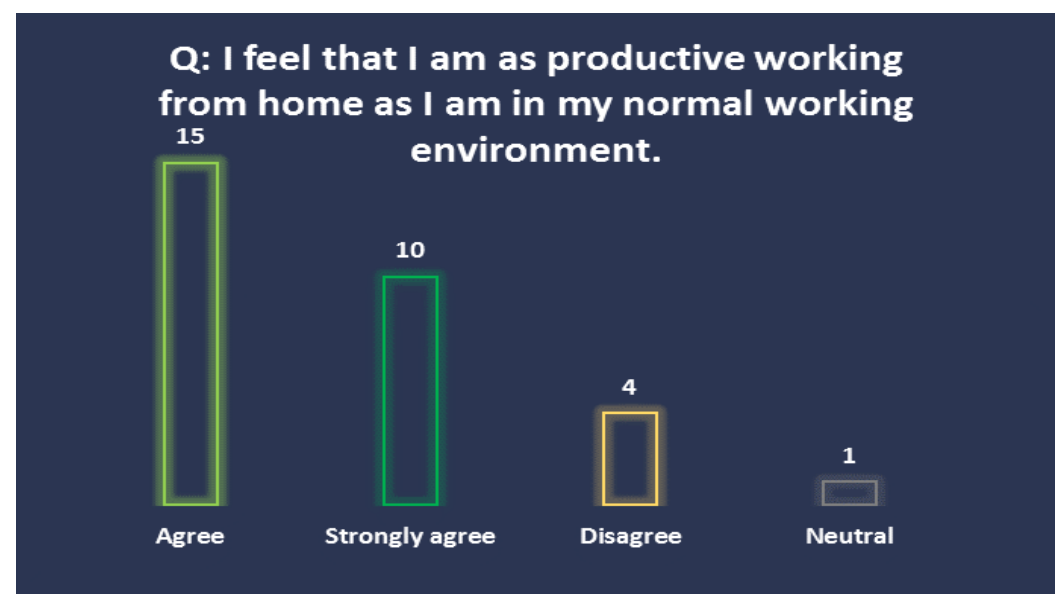

Figure 3. Distribution of the respondents (number) based on their feedback to the survey question related to individual productivity

Source: the authors

In order to have a bigger picture related to the impact of the working from home policy on the team's productivity, the respondents were asked to give their opinion related to the statement "I consider that the team productivity level has decreased since working remotely". $18(60 \%)$ of the respondents disagree with the above statement, 7 (23\%) of them strongly agree, $4(13 \%)$ of the respondents have chosen a neutral opinion, and only 1 respondent agrees. As a conclusion, there is a diversity in the respondents' perception related to the impact of the MWFH regime on the team's productivity. And yet, we can notice that at the level of Team A, the prevailing opinion is that productivity at team level has not decreased due to the MWFH regime compared with the prepandemic period when the work was done in an office.

\section{DISCUSSION AND CONCLUSION}

The context of the COVID-19 pandemic leads to a MWFH regime, respectively the transition in a very short time to $100 \%$ virtual teams. As a result, the organizational context is a unique and unexpected one for the team leaders of the team which has now become $100 \%$ virtual. 
The survey-based research was realized in a $100 \%$ virtual team, from a Shared Service Centre located in Cluj-Napoca, Romania, the time frame being from March 2020 until March 2021. The aspects investigated in this research are the following:

$\checkmark$ Presentation of the activities of the $100 \%$ virtual Team A, which is a complex one, aiming to achieve excellence related to procurement processes and tools, respectively the implementation of the digitalization and governance strategy at a global level. Therefore, the activity of the team members from Team A is represented by performing data analyses, reports and tools fundamental for the strategic initiatives and global procurement projects of the multinational company (such as key performance indicators, dashboards, etc.) in order to drive the achievement of results.

$\checkmark$ Information related to the structure of Team A; this team is led by 2 senior team leaders and one manager, the team being formed by 36 employees, all with university level studies. Also, in Team A there is a slightly higher number of male employees (52\% with the management team included), young, graduates of university studies. It is also worth highlighting the diversity of the employees' specialization that gives a special touch to the Department A, $67 \%$ of the employees had studied areas other than economical science. The youth of the team members is also reflected in the work experience; predominantly, Team A consists of employees with work experience in the range of 4 to 10 years. Likewise, in terms of seniority in this Shared Service, most of the team members are in the range of 1 to 5 years.

$\checkmark$ The organizational context at the level of Team A, in the analysed time frame, is a difficult one to manage by the management of Team A. On one hand, at the entire company level, Team A included, the salary review process didn't take place in 2020; as a result, no additional financial incentives were granted to the employees in 2020. On the other hand, the workload had increased for Team A and implicitly at the level of each employee from this team. In this regard it is important to mention that the COVID-19 pandemic had a major impact on the society and economy, on the transportation industry and this had directly influenced the top management's decision to not have a salary review process in 2020. At the same time, the difficult situation from the transportation industry led to a higher focus from the management team on streamlining internal processes, on performance management, on accelerating the implementation of the governance strategy; all of these led to a workload increase at the overall Team A level. Both decisions are justified, but the simultaneous implementation has created a truly challenging organizational context for the management of Team A.

$\checkmark$ The decisions taken by the top management of the multinational company had a direct impact on Team A's activities, which had the purpose to ensure the continuation of the company operations "in the new normal", due to the COVID-19 pandemic. In this respect, these decisions were focused on ensuring working conditions in the MWFH regime, improving the electronic communication infrastructure and the internal reorganization process of the team.

$\checkmark$ Information related to the decision taken by the management of the analyses team were detailed, in order to ensure optimal working conditions for the employees. In this respect, the decisions were focused on the formal and informal communication, as well as on the personal development of the team members. It should be noted here that these decisions were reviewed by the management of Team A based on the feedback received from the team members (as an example, the daily meetings have been reduced to 3 meetings per week).

$\checkmark$ This process can be part of the learning by doing approach adopted by the leaders of Team A, an essential aspect given by their new situation (employees working from home and the team being $100 \%$ virtual). 
$\checkmark$ Detailing the situation of team A, based on the perception of the team members, after a one-year period of MWFH regime and being part of a $100 \%$ virtual team. It should be noted that according to the undertaken survey, the transition to a full virtual team did not impact the level of team productivity, it even helped to strengthen the independence of the employees in performing the tasks. If the performance indicators of the department were in target, it can however be noticed that the essential aspects related to the level of team connection, sense of belonging and cohesion have been negatively impacted. To these are added other important elements at team level, more specifically, the engagement and coordination level achieved by the management of the team, respectively that there is almost a balance between the number of respondents who chose opposite answers.

Considering all the above mentioned aspects, it is important to highlight that the leaders of Team A possess and use cognitive, social and behavioural capabilities that are predominantly used in the transactional leadership style. Another important aspect is the organizational context from 2020 when the salary review process didn't take place and made the process even more difficult. Therefore, it can be considered that the management of Team A acted very well, showing interest for the personal development of their employees (organizing one to one meetings with main focus on this topic), which indicates the existence of capabilities that fall into the transformational leadership.

In the recommendations part we focus on a set of managerial approaches that can help to strengthen the positive aspects, as well as counteract the negative aspects caused by MWFH at the level of Team A.

$\checkmark$ Regarding the increase of the level of connection of the team members, which was identified at a reduced level, we recommend that the 3 so-called daily sessions per week be complemented by face-to-face interactions. Moreover, taking advantage of the fact that it is allowed to go to the office space, the one to one meeting could take place live in order to socialize, to have a direct and more informal connection. By respecting the social distance rules and occupancy rate of the office, live meetings can be scheduled for teams working on various projects in order to increase the degree of individual connection with the rest of the team. Another recommendation for the direct team leaders is to be interested in aspects related to the personal life of the employees and to provide them psychological support (if they need), to encourage them to have a healthy work-life balance.

$\checkmark$ In order to increase the level of team cohesion, we advise the management of Team A to organize team building activities, adapted to the online environment and by taking into account the proposals from the teams. We also recommend to the management of Team A to check the availability of the team members for live team building activities and if there is interest, we recommend organizing such activities with a certain recurrence of 3-4 months. We consider that this kind of action can foster the increase of employee engagement levels.

$\checkmark$ To increase employee engagement and to retain talents, the management of the team should give arguments to the top management with regards to why it is important to restart the salary review process. It is noticed that a balance is needed between the market offer and the level of remuneration, especially as the employee's profiles from Team A are targeted by fields such as IT or business analysis.

$\checkmark$ Strengthening the transformational leadership style at the level of Team A management by exposing to the specific set of capabilities of this style, respectively providing coaching in order to adopt and use this kind of capabilities.

In the context of COVID-19, the $100 \%$ virtual teams were the ones that ensured the business continuity of the companies in areas suitable for remote work, as in the cases of the SSCs. The team 
leaders of these kinds of teams are faced with numerous challenges, given by the general organizational environment, by the challenges of the virtual teams, respectively the implications of the mandatory work from home regime. The result of the work of the leaders is influenced by the cognitive, social and behavioural capabilities owned by them, these capabilities being specific for both transactional and transformational leadership style.

Finally, a number of research limitations need to be considered. Firstly, there are limitations given by the disadvantages of case study research, such as lack of rigour (Yin, 2009), researchers' own bias (Stake, 1995) and so on. Secondly, given the fact that we are analysing only one virtual team in a multinational company, we need to be careful about the results of the research. As for future research directions, it is intended to replicate this study at the level of other virtual teams from the same multinational company in order to compare the results. Another future direction of research is to identify the main challenges of leading virtual teams during COVID-19 pandemic through the lenses of team leaders from different multinational companies, through qualitative research.

\section{ACKNOWLEDGMENT}

The publication of this article was supported by the 2021 Development Fund of the Babeş-Bolyai University.

\section{REFERENCES}

Andrei, A. M. (2021). Teleworking, Teamwork and Transactive Memory during the COVID-19 Outbreak. Management Dynamics in the Knowledge Economy, 9(3), 393-403. Retrieved October 11, 2021 from https://sciendo.com/article/10.2478/mdke-2021-0026

Anoye, A. B., \& Kouamé, J. S. (2018). Leadership Challenges in Virtual Team Environment. International Journal of Scientific \& Technology Research, 7(7), 160-167. Retrieved April 10, 2021, from https://www.ijstr.org/final-print/july2018/Leadership-Challenges-In-VirtualTeam-Environment.pdf

Bonacini, L., Gallo, G., \& Scicchitano, S. (2021). Working from home and income inequality: risks of a "new normal" with COVID-19. Journal of Population Economics, 34, 303-360, doi: $10.1007 / \mathrm{s} 00148-020-00800-7$.

CIPD (2021). Virtual Teams. Lessons from research, London, UK. Retrieved April 12, 2021 from https://www.cipd.co.uk/Images/developing-virtual-teams-1_tcm18-76431.pdf

Deloitte (2021). Working remotely: setting your team up for success. Retrieved April 14, 2021 from https://www2.deloitte.com/content/dam/Deloitte/ie/Documents/Consulting/deloitte_working_ remotely_success.pdf

Dolce, V., Vayre, E., Molino, M., \& Ghislieri, C. (2020). Far Away, So Close? The Role of Destructive Leadership in the Job Demands-Resources and Recovery Model in Emergency Telework, Social Sciences, 9(196), Retrieved April 14, 2021 from https://www.mdpi.com/2076-0760/9/11/196.

Eurofound. (2020). Living, working and COVID-19. First findings April 2020. retrieved April 10, 2021 from https://www.eurofound.europa.eu/sites/default/files/ef_publication/field_ef_ document/ef20058en.pdf.

EY. (2019). Romania Business Passport. Retrieved April 16, 2021 from https://www.eyromania.ro/assets/Services/bad0fbadb4/EY-Romania-Business-Passport2019.pdf

Hamilton, M. (2009). The interaction of transactional and transformational leadership, Online Journal for Workforce Education and Development, 3(3), 1-11. Retrieved April 10, 2021 from https://opensiuc.lib.siu.edu/cgi/viewcontent.cgi?article=1078\&context=ojwed. 
Iorganda, (Voda), A. M., \& Roman, M. (2020). Work from Home by Occupation in Romania: Initial Assesment in the Context of COVID-19 Pandemic, Proceedings of the International Management Conference, Faculty of Management, Academy of Economic Studies, Bucharest, Romania, 14(1), 811-820. Retrieved April 2, 2021 from http://conferinta.management.ase.ro/ archives/2020/contents.html

Jibai, S., \& Andallah, J. (2019). Particularities of Distance management and Team Leadership, Proceedings of the International Management Conference, Faculty of Management, Academy of Economic Studies, Bucharest, Romania, 13(1), 961-970. Retrieved April 10, 2021 from http://conferinta.management.ase.ro/archives/2019/contents.html

Kniffin, K. M., Narayanan, J., Anseel, F., Antonakis, J., Ashford, S. P., Bakker, A. B., Bamberger, P., Bapuji, H., Bhave, D. P., Choi, V. K., Creary, S. J., Demerouti, E., Flynn, F. J., Gelfand, M. J., Greer, L. L., Johns, G., Kesebir, S., Klein, P. G., Lee, S. Y., Vugt, M. V. (2021). COVID-19 and the workplace: Implications, issues, and insights for future research and action, American Psychologist, 76(1), 63-77. Retrieved April 9, 2021 from https://psycnet.apa.org/fulltext/2020-58612-001.pdf

Mukherjee, D., Lahiri, S., Mukherjee, D., \& Billing, T. K. (2012). Leading virtual teams: how do social, cognitive, and behavioral capabilities matter? Management Decision, 50(2), 273-290. Retrieved April 14, 2021 from, http://personal.kent.edu/ dmukherj/Management DecisionPaper.pdf

PwC. (2020). 100\% Remote: Managing Teams Working from Home. Retrieved April 14, 2021 from https://www.pwc.com/jg/en/issues/covid-19/hundred-percent-remote.pdf

Stake, R. E. (1995). The Art of Case Study Research, SAGE.

Yin, R. K. (2009). Case study research: Design and methods. SAGE. 